\title{
Política y Educación
}

\author{
For el R. P. FELIPE MAC GREGOR, S. J. \\ Catedrático titular de la Facultad de Letras \\ de la Pontificia Universidad Católica del Perú.
}

El delicado encargo recibido del $\mathrm{V}$ Congreso Interamericano de Educación Católica, reunido recientemente en Santiago, Chile, de planear la organización de un Seminario Interamericano sobre la Libertad de Enseñanza, me ha obligado a precisar varias reflexiones sobre los dos puntos que enuncian el título de éste: "Política y Educación". Un esquema provisional del orden y trabazón de esas reflexiones, es lo que presento a continuación.

En tres sentidos se emplea en el curso de esta exposición la palabra "política" y en cada una de estas acepciones procuraré presentar la íntima relación que ella guarda con la educación. No parece necesario extenderse en la significación precisa del término de educación.

Política significa el gobiemo de los grupos humanos, ciudades, esta. dos, nacido no de la arbitrariedad del despotismo, ni de la imposición del arrivista, sino del recto funcionamiento del organismo social.

$Y$ una de las funciones que todo gobierno realiza en el orden histórico temporal es la de educar. Por eso todos los códigos de gobierno y las Constituciones de los Estados se ocupan de la educación. Y esta preocupación es más discernible aún, en los antecesọres más próximos de las legislaciones modemas: el Código Prusiano, el Código de Napoleón y la Constitución de Có́diz de 1812.

De la Constitución de Cádiz dependen especialmente nuestras Constituciones. Las primeras la siguieron casi literalmente en algunos de sus artículos sobre la educación. La actual se ocupa del tema en el Título III, Arts. $71 \propto$ 83, y en el Art. 192, que es de excepcional importancia en la materia.

Política significa, en segundo lugar, el juego, la actividad de los grupos humanos, que forman esquemas ideológicos, planes de reclizaciones gubernativa y tácticas para la consecución del poder, estructurando así los partidos políticos.

Los partidos políticos, por su relación al gobierno que buscan y sobre todo por su aspiración de dominio de las mayorías, se apoyan necesariamente en la educación. Y cuanto más "comprensivo" (en el sentido lógico 
del término), sea un partido, cuanto mós totalitario sea (para usar el término hoy aceptado), más buscará, se apoyará y descansaró en la educación.

Polílica significa, finalmente, la ciencia y el arte del gobierno. Ciencia por el estudio de las causas primeras y arte por la búsqueda de las reglas generales. La ciencia y el arte del gobierno, claro está, no pueden desentenderse de estudiar la Educación.

$Y$ entre estas acepciones de Política, es obvio que debe existir una correlación que estabiezca su prioridad.

Cuando los primeros hombres tuvieron que gobemar, no recurrieron a tratados que expusieran la ciencia del gobierno, así como tampoco los primeros escultores consultaron tratados de escultura. Pero, ies hoy justificable que un hombre quiera gobernar como si Maquiavelo, Montesquieu, la Revolución Francesa o la Revolución Rusa, no hubieran existido?

No parece que haya que detenerse en probar el primado de la ciencia política, sobre la mera acción de gobernar o sobre el juego de intereses de partido.

La ciencia de la Política en su trama intelectual se entrelaza con otros tres dominios del saber: el derecho, la técnica y la economía.

La base de la ciencia del gobierno es el derecho, el del individuo y el de la sociedad, y no sólo el derecho abstracto, sino los derechos concretos que el hombre tiene y que la autoridad política no da, sino garantiza.

Hay que llamar poderosamente la atención de los hombres de hoy sobre esta interdependencia entre gobierno, poder y derecho si finalmente la paz en los estados $\mathrm{y}$ en las naciones va a ser una realidad. $\mathrm{Y}$ todo gobernante debe posesionarse plenamente de la verdad de que lo que construya políticamente violando o conculcando derechos, se parece a lo que el arquitecto quiera hacer desafiando la ley de la gravedad.

El derrumbe de las organizaciones poderosas de los Estados modernos nace precisamente de aquí.

Frente a las tremendas monstruosidades gubernamentales que ha vivido el sigio $\mathrm{XX}$ en los regímenes totalitarios, intuitivamente han recurrido los hombres a la promulgación de sus derechos fundamentales y ese es el sentido de la Carta de los Derechos Humanos proclamada por la Asamblea de las Naciones Unidas en París, en el año 1948.

El gobiemo es la prosecución del bien común en el marco del derecho, y no puede siquiera concebirse una prosecución, una búsqueda del bien de la colectividad, si no se conoce y si no se respeta la exigencia de la técnica, es decir, la apiisación de los conocimientos a la solución práctica de los problemas. ¿Tendría hoy sentico la campaña sanitaria de un Estado para extirpar la malaria sin usar el DDT? ¿Puede planearse hoy el progreso de un país sin tener en cuenta la energía atómica, la aviación o el uso de las radiciciones?

Pero el Ejercicio de un derecho, el uso de la técnica, se ven condicionados por la economía. El Estado que quiera dar a todos sus campesinos oportunidad de aprender asistiendo a escuelas radiofónicas, sólo puede lograrlo si tiene los medios económicos para hacerlo. 
Resulta entonces que la conjunción armoniosa del derecho, la técnica y la economía regulan los supremos principios por los que se rige la ciencia del gobierno. talista.

Gobernar para la economía fué el errō̄ del individualismo capi-

Gobernar para la técnica es el error del colectivismo materialista. berales.

Gobernar para el puro derecho puede ser la utopía de muchos li-

¿Y qué dicen estas tres fuentes del buen gobierno respecto de la educación?

¿Qué dice el Derecho? Por encima de leyes particulares o declaraciones incompletas que sirven $\alpha$ un momento del interés político, hay que analizar el ser profundo de las cosas y del hombre, de la familia, del Estado.

Hay que escudriñar instituciones jurídicas tales como la patria potestad, tan adentradas en nuestra historia cultural como el derecho mismo.

Hay que leer con ese espíritu la Declaración de los Derechos Humanos, que dice: "los padres tendrán el derecho preferente de escoger el tipo de educación que ha de darse a cada uno de sus hijos" (Art. 26).

Una expresión de este mismo derecho es la sentencia famosa de la Corte Suprema de los Estados Unidos en el caso en que un padre de familia litigó con el Estado de Oregón porque quería obligarlo a enviar a sus hijos a las Escuelas del Estado. La Corte decidió que el hijo pertenece a los padres y que éstos tienen el derecho y la obligación de educarlos.

La técnica en la educación significa el progreso de los sistemas, métodos, instrumentos pedagógicos. Es claro que en un régimen de monopolio estatal el progreso de la técnica educacional está excepcionalmente restringido por la centralización y administración estatal. Y esta nueva consideración apriorística, se ve comprobada experimentalmente por la realidad educacional de los países.

Donde el régimen de monopolio estatal impera, el progreso técnico de la enseñanza es lento $y$ sujeto a mil vicisitudes. $Y$, por el contrario, en los países donde hay una libertad académica sana, no se habla de esas "crisis" y reformas frecuentes a que nos tienen tan acostumbrados la crónica de nuestra realidad educativa.

Economía significa también en educación, lo mismo que en los otros dominios de la vida humana, el viejo arte casero de buscar ingresos para el sustento y administrarlos mejor. La obra de educar reclama gastos de varios órdenes: construcción y mantenimiento de locales, preparación del profesorado, sostenimiento del profesorado, servicios auxiliares.

Estos gastos, cuando el empleador es el Estado, son generalmente mucho mayores en todos los países del mundo. Han sido publicados estudios detallados que analizan y comparan los costos de la enseñanza particular y fiscal en Colombia, en el Perú. El Ministerio de Educación Pública del Brasil en el estudio oficial publicado como antecedente de la ley que crea el Fondo de Ayuda a la Enseñanza Meḑia, dice textualmente:

"Las estadísticas de apreciación, a que ya nos hemos referido, muestran que el costo medio por alumno en la segunda enseñanza, fué, en 1951, 
de 1,978 cruzeiros en la escuela particular y 6,984 cruzeiros en la escuela oficial.

"Aunque la enseñanza particular sea ofrecida a precio notablemente inferior al costo de la enseñanza oficial, existe la inamovible tendencia de juzgar las contribuciones exigidas por la escuela particular, como excesivas en la comparación que se establece con la gratuidad de la escuela públi$\mathrm{ca}^{\prime \prime}$. ("Documentario").-Fundo Nacional do Ensino Médio. - 5 Junho de 1955.-Página 26).

En Chile, el Estado subvenciona a los Colegios gratuitos con el $50 \%$ del costo por alumno al Estado en el ejercicio fiscal anterior.

$Y$ desde que esa ley de subvenciones fué aprobada, la Escuela Estatal ha subido en un $32 \%$ de matrícula y la escuela privada en un $157 \%$, lo que quiere decir que el número real de alumnos en Educación Secundaria en Chile habría aumentado sólo en $78 \%$, privándose así a un $78 \%$ de jóvenes adolescentes del derecho a educarse, que naturalmente poseen, si no se hubiese dado la ley del subsidio.

Esto dice la ciencia del gobierno en materia educacional cuando se la ilumina con los principios del Derecho, de la economía y de la técnica.

Los que gobieman, a veces no lo saben o no les interesa saberlo $y$ por esto en muchos países de América y de Europa se continúa aún con la rutina del monopolio, con el derroche innecesario por asumir el Estado todos los costos de la enseñanza con la ineficacia práctica de lo enseñado, con la enorme complejidad de las reformas educacionales verticales y uniformes.

Menos aún les interesa a los partidos, que son oportunistas, atender a las exigencias de la ciencia del gobiemo en materia educativa. La maquinaria estatal de educación se ha convertido en una burocracia tan enorme que ofrece muchos lugares para colocar $\alpha$ amigos, satisfacer a correligionarios, etc. $Y$ si se consideran los partidos verticales, totalitarios, que no sólo pretenden influir en la gestión de la causa pública, sino sobre todo dominar las mentalidacies, es más claro aún por qué no les interesa la ciencia del gobiemo.

Frente a esta situación compleja y oscura que reina en muchos países y también en nuestro país, ¿qué debemos hacer nosotros, los profesores y los maestros?

Yo creo que nuestra misión es doble, recordando el famoso verso de Tennyson, diría que nuestra primera obligación es "jurar un solemne juramento", prometiendo alejar del dominio de la educación el interés partidista. En frase que parece paradojal, pero que es profundamente cierta, la educación debe ser la tierra de nadie en política de partidos, porque es la tierra de todos, porque la exigencia de bien, de belleza y de bondad que las generaciones jóvenes del Perú tienen, sólo se satisface con el bien, la belleza y la bondad y no con la parcelación de éstos al servicio de intereses de grupos. 
Por ser hombres de estudio, nuestra misión debe ser la de informar $\alpha$ los que gobiernan, $\alpha$ los que, absorbidos por la urgencia de hacer, quiź́ no tienen la oportunidad de pensar, y decirles que la manera eficaz de lograr el progreso educacional que ellos desean es acomodar su acción a las exigencias del saber. 